\title{
Hilar tumours
}

\author{
Guido Costamagna MD FACG, Andrea Tringali MD, Lucio Petruzziello MD, Cristiano Spada MD
}

\section{G Costamagna, A Tringali, L Petruzziello, C Spada. Hilar tumours. Can J Gastroenterol 2004;18(7):451-454.}

Tumours that involve the confluence of the bile ducts in the liver hilum provide a major therapeutic challenge. Adequate palliation requires relief of jaundice. Even though jaundice can be relieved if only $30 \%$ of the liver is drained, the presence of undrained bile ducts may result in pruritus and a continued risk of cholangitis and hepatic abscess. The biliary anatomy is defined by cholangiography, which today can be performed by magnetic resonance; the stricture is dilated, and plastic or metallic stents are endoscopically inserted over a guidewire. Patients with complex hilar strictures may benefit from the insertion of one or more stents, although there is debate about how many are necessary. The present article provides specific technical details, describes comparative trials of unilateral versus bilateral biliary drainage and explores new techniques that warrant further investigation.

\section{Les tumeurs hilaires}

Les tumeurs qui touchent la confluence des canaux cholédoques dans le hile hépatique représentent un important défi thérapeutique. Une palliation pertinente exige de soulager la jaunisse. Même s'il est possible d'y parvenir en ne drainant que $30 \%$ du foie, la présence de canaux cholé doques non drainés peut provoquer un prurit et un risque constant de cholangite et d'abcès hépatique. L'anatomie biliaire se définit par cholangiographie, qui peut maintenant être effectuée par résonance magnétique, dilatation des rétrécissements et insertion endoscopique d'extenseurs métalliques ou de plastique sur un fil-guide. Les patients présentant des rétrécissement hilaires complexes peuvent bénéficier de l'insertion d'au moins un extenseur, même si on ne s'entend pas sur le nombre nécessaire. Le présent article fournit des détails techniques précis, décrit les essais comparatifs du drainage biliaire unilatéral par rapport au drainage bilatéral et présente de nouvelles techniques qui méritent des explorations plus poussées.

Key Words: Cholangitis; Endoscopic drainage; Hilar stricture; Jaundice; Klatskin tumour

$\mathrm{T}$ he management of malignant tumours involving the main hepatic confluence ('hilar tumours') remains a major clinical issue despite significant progress in the past few years. The bile ducts can be involved by primary cancer (cholangiocarcinoma or 'Klatskin tumour'), contiguous spread from gallbladder, pancreatic or hepatocellular carcinoma, or lymph node metastases from distant tumours. One should note that the proper term is 'hepatic confluence' and not 'bifurcation' of the bile ducts in the hilum, which reflects the direction of bile flow.

Only a minority of patients are candidates for surgical resection at the time of diagnosis (eg, $15 \%$ to $40 \%$ of those with cholangiocarcinoma), mainly because of the presence of either vascular invasion or metastases. Palliation of biliary or intestinal obstruction and pain has, therefore, become a major therapeutic goal. Achievement of palliation requires a thorough understanding of hepatobiliary anatomy (Figure 1) as well as localization and staging of the tumour. The Bismuth-Corlette classification of hilar cholangiocarcinoma is based on the degree of involvement of the main and secondary hepatic confluences (1) (Table 1). Representative cholangiograms are shown in Figure 2.

Because of its remarkable efficacy and low morbidity and mortality, endoscopic stenting has become the modality of choice for relieving obstructive jaundice in cases of inoperable hilar strictures. Furthermore, this technique can be used as a preoperative measure for potentially resectable lesions and for patients who might be candidates for adjuvant treatment, including photodynamic and radiation therapy (2-5).

\section{TECHNIQUE OF BILIARY STENTING}

Complete cholangiography, which determines the precise location and extent of the hilar stricture, is the first step in planning effective biliary drainage. In previous years it was obtained by endoscopic retrograde cholangiopancreatography (ERCP). Nowadays, magnetic resonance cholangiopancreatography (MRCP) can provide detailed imaging with precise delineation of the hilar stricture without the need for an invasive procedure such as ERCP or percutaneous transhepatic cholangiography. There is reasonable agreement between the two techniques in determining the stage of cholangiocarcinoma, according to Bismuth-Corlette stage (Table 2) (6).

Biliary sphincterotomy is often undertaken, especially if it is anticipated that more than one stent will be inserted, but is not mandatory if the papillary orifice is sufficiently patent or has been mechanically dilated already. Sphincterotomy may also be precluded by the presence of a significant bleeding disorder.

A guidewire is then advanced through the stricture into the obstructed bile ducts. Hydrophilic guidewires are preferred because they are easier to pass through the stricture than

Digestive Endoscopy Unit, Università Cattolica del Sacro Cuore, Rome, Italy

Presented at the $16^{\text {th }}$ International Course on Therapeutic Endoscopy, Toronto, Ontario, October 2003

Correspondence and reprints: Dr G Costamanga, Digestive Endoscopy Unit, Università Cattolica del Sacro Cuore, Largo A Gemelli 8

00168 Rome, Italy. Telephone +39-0635511515, fax +39-0630156581, e-mail gcostamagna@rm.unicatt.it

Received and accepted for publication May 10, 2004 


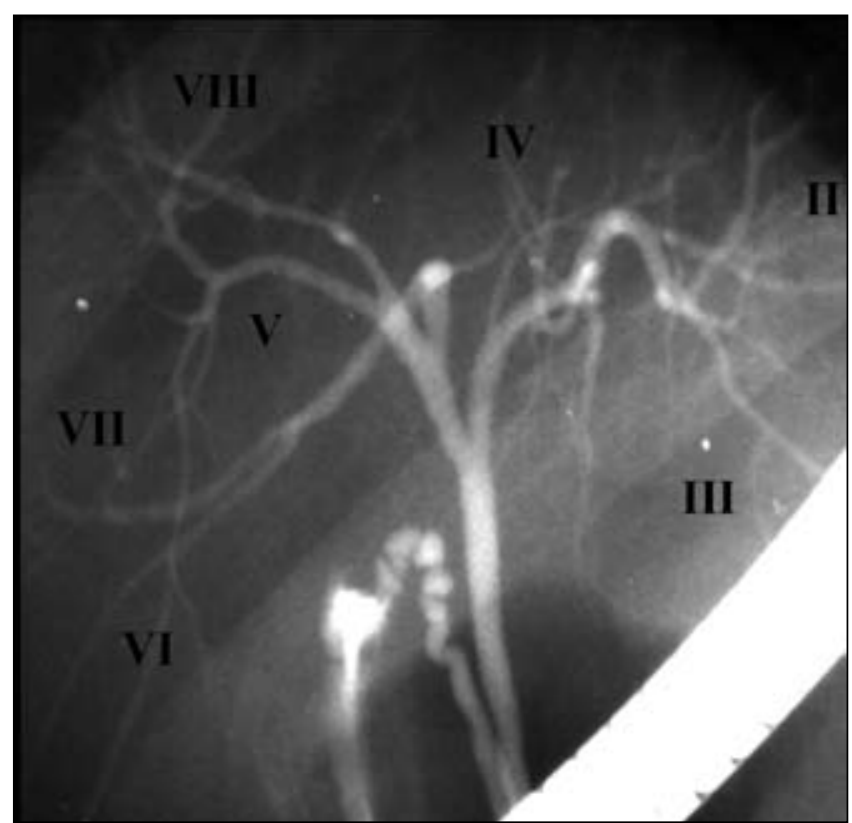

Figure 1) Retrograde cholangiography showing correspondence between intrahepatic ducts and hepatic segments

TABLE 1

Bismuth-Corlette classification of hilar tumours

\begin{tabular}{lll}
\hline Type & Definition & $\begin{array}{c}\text { Number of stents } \\
\text { for complete drainage }\end{array}$ \\
\hline I & $\begin{array}{l}\text { Stricture does not interrupt the main } \\
\text { hepatic confluence }\end{array}$ \\
II & Stricture interrupts the main hepatic confluence & 2 \\
IIIa & Stricture interrupts the main and the right \\
$\quad$ secondary hepatic confluence \\
IIIb $\quad$ Stricture interrupts the main and the left \\
$\quad$ secondary hepatic confluence \\
IV $\quad$ Primary and both, right and left, secondary \\
$\quad$ hepatic conflence are interrupted \\
\end{tabular}

Modified from reference 1

Teflon-coated guidewires. When indicated, tissue sampling (either brush cytology or endoluminal forceps biopsy) should be carried out before stenting. The specificity of such techniques is impressive (approaching 100\%) but their sensitivity ranges from only $15 \%$ to $70 \%$ (7). Tight strictures may be dilated before stenting, using bougies, coaxial dilating catheters or balloons (pneumatic dilation).

A plastic guiding catheter is then advanced over the guidewire and a plastic stent is inserted over the guidewirecatheter complex using another coaxial pushing catheter of the same size. Large bore (10 Fr) polyethylene or Teflon stents are generally used, because they have been shown to remain patent for significantly longer periods of time than do narrower devices (8). However, there is no significant advantage for 11.5 Fr over $10 \mathrm{Fr}$ stents (9). Multiple plastic stents are required in cases of complex hilar strictures. In such cases, it is preferable to place the first stent into the left hepatic duct due to its acute angle resulting in more difficult stent placement. When inserting more than one stent, it is important first to insert all the necessary guidewires in the ducts chosen for

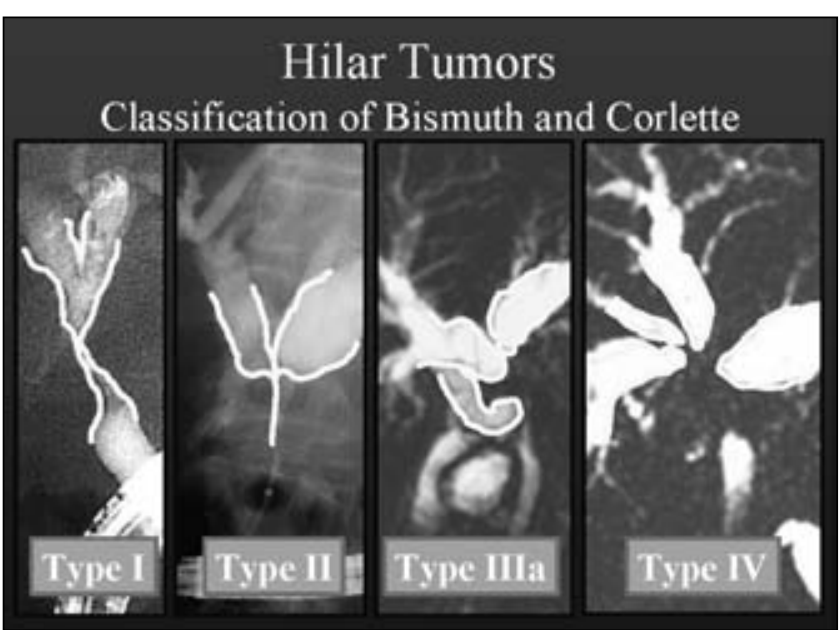

Figure 2) Bismuth-Corlette classification of hilar tumours

TABLE 2

Degree of agreement between endoscopic retrograde cholangiopancreatography/percutaneous transhepatic cholangiography (ERCP/PTC) and magnetic resonance cholangiopancreatography (MRCP) in staging hilar tumours

\begin{tabular}{|c|c|c|c|c|}
\hline \multirow[b]{2}{*}{ MRCP Stage } & \multicolumn{4}{|c|}{ ERCP/PTC Stage } \\
\hline & I & II & III & IV \\
\hline I & 6 & & & \\
\hline II & 2 & 5 & 1 & \\
\hline III & & 1 & 10 & 2 \\
\hline IV & & & & 5 \\
\hline
\end{tabular}

Adapted from reference 6

drainage, to maintain access to each blocked duct after the first stent has been placed. Self-expandable metal stents (SEMS), which usually achieve a maximum diameter of $30 \mathrm{Fr}$, can be placed over the guidewire with or without preliminary dilation of the stricture. Most authors recommend the use of uncovered SEMS for hilar tumours, to avoid complete blockage of the other biliary branches.

High-volume centres enjoy a technical success rate for endoscopic stent placement of nearly 90\% (10). Clinical success (ie, palliation of jaundice and pruritus) can be expected in more than $80 \%$ of patients in whom incomplete drainage of the bile ducts has been achieved $(11,12)$.

\section{HOW MUCH DRAINAGE IS ENOUGH?}

The goal of palliation in cases of obstructive jaundice is to relieve cholestasis, which requires complete drainage of the intrahepatic ductal system. In practice, stent placement that drains $30 \%$ of the liver may alleviate jaundice but not cholestasis. The remaining obstructed ducts provide a continued risk of cholangitis and hepatic abscess (13).

The number of stents needed to drain a malignant hilar stricture should be equal to the number of obstructed ducts at the primary and secondary (right or left) hepatic confluence. For example, three stents would be required for a BismuthCorlette type III stricture. Moreover, biliary anatomy may complicate efforts to obtain endoscopic drainage: anatomical 
variants involving the right hepatic duct system (eg, right sectorial duct originating from the left hepatic duct) occur in at least $40 \%$ of the general population.

Some authorities recommend that only a single hepatic lobe be drained, claiming no differences in outcome $(11,12)$. A recent randomized trial undertaken by De Palma et al (14) addressed this issue. They assigned 157 consecutive patients with malignant hilar obstruction to either unilateral (group A) or bilateral (group B) hepatic duct drainage. The two groups were comparable in terms of tumour origin and BismuthCorlette stricture type. Results are summarized in Table 3. In the intention-to-treat analysis, patients in group A had significantly higher rates of successful stent insertion and successful drainage and a lower incidence of early complications, mainly because of fewer cases of cholangitis. The rates of late complications (in patients who had survived at least 30 days) and median survival were comparable in the two groups. In the per-protocol analysis (which evaluated only patients in whom stent placement had been successful), there were no significant differences in rates of effective drainage, complications or survival. The results of this study suggested that there was no advantage to attempting bilateral drainage.

The De Palma study (14), however, is far from being free of bias. For example, approximately $30 \%$ of the patients in both groups had a Bismuth-Corlette type I stricture, which clearly does not require bilateral drainage. Detailed subgroup analysis of these patients was not undertaken, so it is not possible to determine how their inclusion may have affected the results. Furthermore, the authors did not compare complete with incomplete drainage, but only one versus two stents, even in patients with Bismuth-Corlette type III strictures (which require three stents to achieve complete drainage). The high rate of early and late cholangitis in patients with complex strictures could be attributed to the presence of injected and undrained bile ducts.

Chang et al (10) found that bilateral drainage is associated with lower sepsis-related morbidity and mortality and longer mean survival, at least when there has been contrast injection into both lobes. A previous study also demonstrated longer survival in patients who have undergone complete drainage of the biliary tree (13).

Placement of one or more metallic stents is an alternative option for patients with complex hilar obstruction. A recent study (15) showed that the insertion of unilateral (in 28 patients) or bilateral (in nine patients) uncovered metallic stents alone provided definitive palliation in $69 \%$ of patients with hilar cholangiocarcinoma, with an overall median survival of 149 days. Even better results have been reported in a recent series of 61 patients who underwent unilateral placement of SEMS: successful drainage was achieved in $96.7 \%$, late stent occlusion occurred in $22.9 \%$ and median survival was 140 days (16). It is still unknown, however, if complete drainage with metallic stents provides a superior clinical outcome.

\section{FUTURE DIRECTIONS AND UNRESOLVED ISSUES}

Hintze and colleagues (17) recently evaluated the utility of MRCP in 35 patients with unresectable Klatskin tumours (13 type III and 22 type IV). This procedure yields excellent images of both patent and dissociated bile ducts, potentially
TABLE 3 Unilateral versus bilateral hepatic duct drainage for malignant hilar obstruction

\begin{tabular}{lccc}
\hline Criterion & Unilateral & Bilateral & P \\
\hline Successful stent insertion (\%) & 88.6 & 76.9 & $<0.05$ \\
Successful drainage (\%) & 81 & 73 & $<0.05$ \\
Early complications (\%) & 18.9 & 26.9 & $<0.05$ \\
Early cholangitis (\%) & 8.8 & 16.6 & $<0.05$ \\
Late complications (\%) & 39.7 & 39.1 & $\mathrm{NS}$ \\
30-day mortality (\%) & 11.3 & 14.1 & $\mathrm{NS}$ \\
Median survival (days) & 140 & 142 & $\mathrm{NS}$ \\
\hline
\end{tabular}

Data from reference 14. NS Not significant

identifying the best segment(s) to drain. During ERCP, after radiological cannulation with a guidewire and a catheter of appropriate duct, contrast was injected proximally to the stricture avoiding opacification of other ducts. A single plastic 10 Fr stent was inserted in the opacified duct. Using this technique, technical success was achieved in $100 \%$ of cases and clinically successful drainage in $86 \%$ of patients. Only two patients $(6 \%)$ experienced cholangitis in the first 30 days, despite the lack of antibiotic prophylaxis. Survival rates were $94 \%$ at one month and $48 \%$ at one year.

Stent placement can be combined with chemotherapy, external radiotherapy and intraluminal brachytherapy, in which a radiation source (in the form of iridium-192 wire) is inserted through a nasobiliary catheter into the malignant stricture. Morganti and colleagues (18) treated 20 patients with biliary tract cancer, 16 of whom had unresectable and four who had residual disease. Eleven of the 20 had Klatskin tumours, eight had common bile duct cancer and one had gallbladder carcinoma. They administered 5 -fluorouracil and external beam radiation therapy (40 Gy to $50 \mathrm{~Gy}$ ) to all patients, and intraluminal brachytherapy (iridium-192, 30 Gy to 50 Gy) to 12 patients. Eight of the patients experienced mild to moderately severe gastrointestinal toxicity, and two patients who received brachytherapy developed duodenal ulceration. Of the 12 patients who received brachytherapy, four achieved a clinical response (two complete and two partial). The median survival was 21.2 months, and two of the patients with unresectable disease survived longer than five years.

\section{CONCLUSIONS}

More investigation is required to refine endoscopic and other techniques, and adapt them to the specific characteristics of the underlying disease. We still need to determine whether complete drainage of the obstructed biliary tree, using multiple stents, is necessary to achieve adequate palliation, because published studies have yielded conflicting results. Preliminary evidence suggests that incomplete drainage may reduce morbidity from cholangitis. The role of MRCP should be defined. The relative merits of uncovered metallic versus plastic stents must be explored. Finally, more work needs to be done with adjunctive techniques, including intraluminal brachytherapy, photodynamic therapy and high-frequency ultrasonography. 


\section{REFERENCES}

1. Bismuth H, Corlette MB. Intrahepatic cholangioenteric anastomosis in carcinoma of the hilus of the liver. Surg Gynecol Obstet 1975;140:170-8.

2. Wiedmann M, Caca K, Berr F, et al. Neoadjuvant photodynamic therapy as a new approach to treating hilar cholangiocarcinoma: A phase II pilot study. Cancer 2003;97:2783-90.

3. Gonzalez Gonzalez D, Gouma DJ, Rauws EA, van Gulik TM, Bosma A, Koedooder C. Role of radiotherapy, in particular intraluminal brachytherapy, in the treatment of proximal bile duct carcinoma. Ann Oncol 1999;10(Suppl 4):215-20.

4. Dumoulin FL, Gerhardt T, Fuchs S, et al. Phase II study of photodynamic therapy and metal stent as palliative treatment for nonresectable hilar cholangiocarcinoma. Gastrointest Endosc 2003;57:860-7.

5. Ortner MA, Liebetruth J, Schreiber S, et al. Photodynamic therapy of nonresectable cholangiocarcinoma. Gastroenterol 1998;114:536-42.

6. Manfredi R, Brizi MG, Masselli G, et al. Malignant biliary hilar stenosis: MR cholangiography compared with direct cholangiography. Radiol Med 2001;102:48-54.

7. De Bellis M, Sherman S, Fogel EL, et al. Tissue sampling at ERCP in suspected malignant biliary strictures (Part 2). Gastrointest Endosc 2002;56:720-30.

8. Pedersen FM. Endoscopic management of malignant biliary obstruction. Is stent size of 10 French gauge better than 7 French gauge? Scand J Gastroenterol 1993;28:185-9.

9. Pereira-Lima JC, Jackobs R, Maier M, et al. Endoscopic biliary stenting for the palliation of pancreatic cancer: Results, survival predictive factors, and comparison of 10-French with 11.5-French gauge stents. Am J Gastroenterol 1995;91:2179-84.
10. Chang WH, Kortan P, Haber GB. Outcome in patients with bifurcation tumors who undergo unilateral versus bilateral hepatic duct drainage. Gastrointest Endosc 1998;47:354-62.

11. Polydorou AA, Chisholm EM, Romanos AA, et al. A comparison of right versus left hepatic duct endoprosthesis insertion in malignant hilar biliary obstruction. Endoscopy 1989;21:266-71.

12. Polydorou AA, Cairns SR, Dowsett JF, et al. Palliation of proximal malignant biliary obstruction by endoscopic endoprosthesis insertion. Gut 1991;32:685-9.

13. Devière J, Baize $M$, De Toeuf J, et al. Long-term follow-up of patients with hilar malignant stricture treated by endoscopic internal biliary drainage. Gastrointest Endosc 1988;34:95-101.

14. De Palma GD, Galloro G, Siciliano S, et al. Unilateral versus bilateral endoscopic hepatic duct drainage in patients with malignant hilar biliary obstruction: Results of a prospective, randomized, and controlled study. Gastrointest Endosc 2001;53:547-53.

15. Cheng JLS, Bruno MJ, Bergman JJ, et al. Endoscopic palliation of patients with biliary obstruction caused by nonresectable hilar cholangiocarcinoma: Efficacy of self-expandable metallic wallstents. Gastrointest Endosc 2002;56:33-9.

16. De Palma GD, Pezzullo A, Rega M, et al. Unilateral placement of metallic stents for malignant hilar obstruction: A prospective study. Gastrointest Endosc 2003;58:50-3.

17. Hintze RE, Abou-Rebyeh H, Adler A, et al. Magnetic resonance cholangiopancreatography-guided unilateral endoscopic stent placement for Klatskin tumors. Gastrointest Endosc 2001;53:40-6.

18. Morganti AG, Trodella L, Valentini V, et al. Combined modality treatment in unresectable extrahepatic biliary carcinoma. Int J Rad Oncol Biol Phys 2000;46:913-9. 


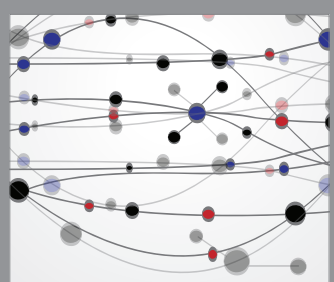

The Scientific World Journal
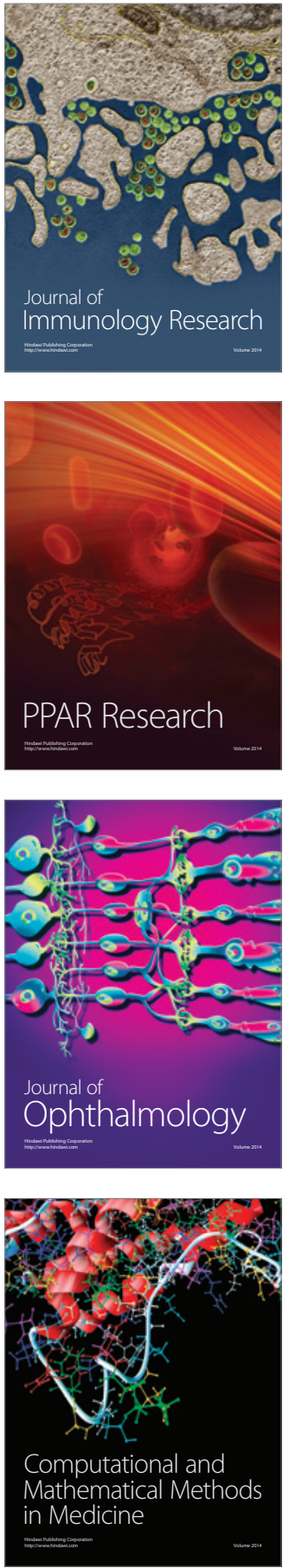

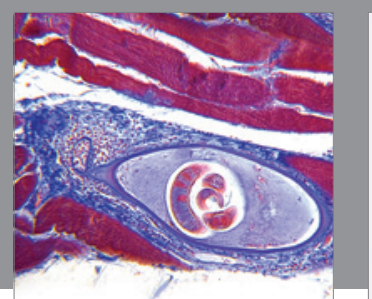

Gastroenterology Research and Practice

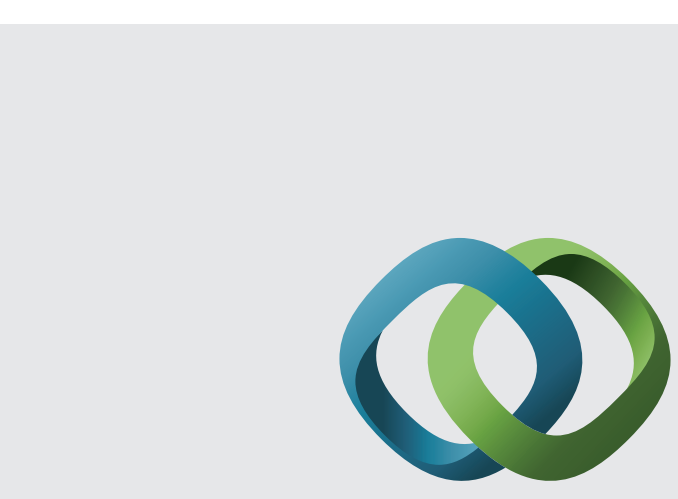

\section{Hindawi}

Submit your manuscripts at

http://www.hindawi.com
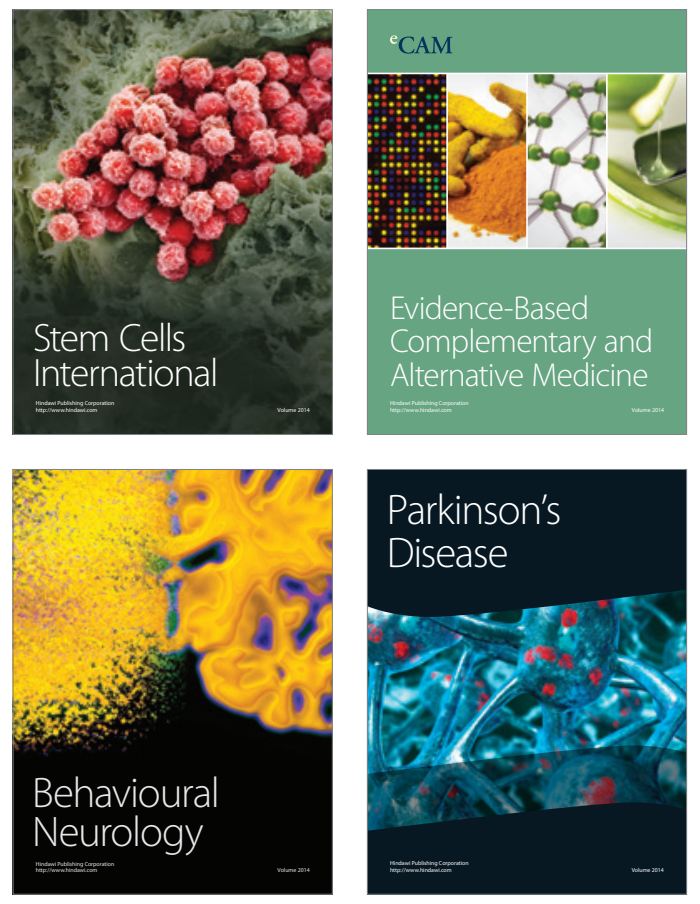
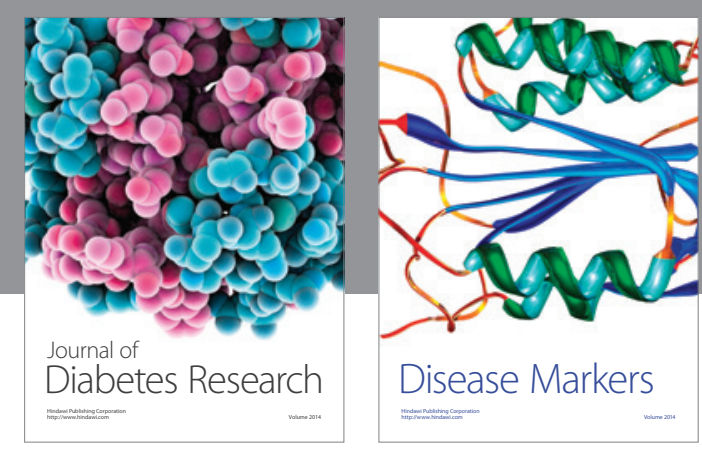

Disease Markers
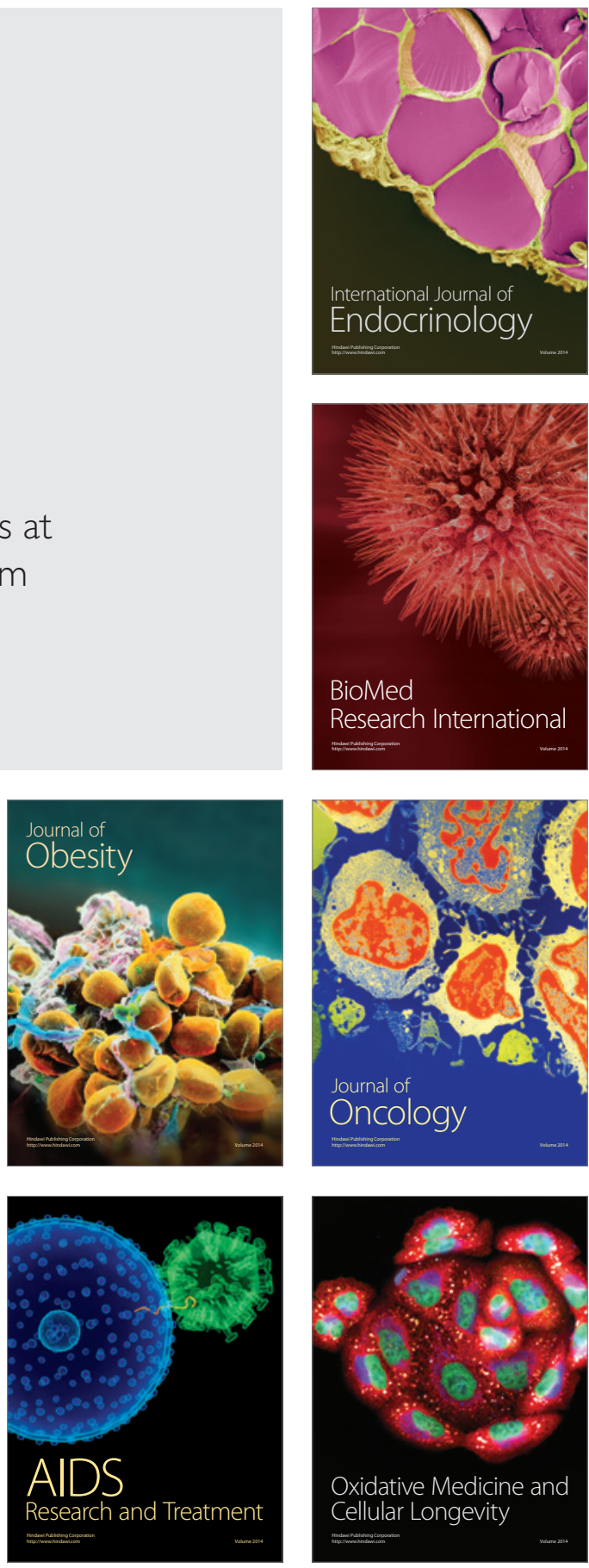